\title{
Introduction Towards a culture of non-simultaneity?
}

\author{
Hanns-Georg Brose
}

\begin{abstract}
There are three different concepts and analytical aspects of social time in contemporary western societies that are referred to in this article: (1) the different tempos of social processes and (2) the varying time horizons of 'socially expected durations' (Merton, 1986). It is argued that due to spatial, technological and socio-economic changes a third, more fundamental evolution of temporality is emerging: (3) an increasing simultaneity of events in our 'world at reach' (Schutz and Luckmann, 1983). The different tempos and time-scopes being causes and effects of this phenomenal simultaneity. An increase in simultaneity necessarily provokes an increase in non-simultaneity. 'Classical' mechanisms of temporal ordering of non-simultaneous events are sequencing and linear processing. It is claimed, that these mechanisms, typical of industrial modernity, are complemented by efforts and exigencies of coping with complexity in a simultaneous mode. It is assumed that the abilities of actors and social systems of parallel and simultaneous processing are enhanced but after all remain limited. Therefore, a growing realm of non-simultaneity remains open to meaningful interpretation. This is what significance an emerging culture of nonsimultaneity has. KEY WORDS • non-simultaneity • short-termism • social time $\bullet$ synchronization $\bullet$ tempo
\end{abstract}

\section{Introduction}

It is conventional wisdom among social-scientists that processes of social change as well as conditions of stability or inertia in social systems can best be understood when we attempt to see the way social time is conceptualized and organized. Or as Karl Mannheim (1936/1976) put it, with reference to the

Time \& Society copyright @ 2004 SAGE (London, Thousand Oaks, CA and New Delhi) VOL. 13 No. 1 (2004), pp. 5-26 0961-463X DOI: 10.1177/0961463X04040740

www.sagepublications.com 
mentality of collective actors: 'The innermost structure of the mentality of a group can never be as clearly grasped as when we attempt to understand its conception of time in the light of its hopes, yearnings and purposes' (p. 188; see also Spurk, this issue).

About two decades since, these collectively shared ideas about the purposes, hopes and yearnings, about the future of Industrial Societies are called into question. The future lost its openness, its character of being a 'storehouse of possibilities' (Luhmann, 1976) and turned into a storehouse of risks and uncertainties (Beck, 1986). In terms of conceptions of time, this came to be expressed by a loss of future orientation, emphasizing discontinuities and uncertainties and hence the perforation of the linearity of time.

The model of social evolution as a continuously progressing prosperity lost the relevance (Lutz, 1984) it had during the period after the Second World War. It seemed to have come to an end: the end of mass-production, the end of work, the end of modernity, etc. But the newly emerging structures could only be grasped by their temporal relation to what had been 'before', as post-industrial and post-modern (Brose, 1987).

As a way out of this kind of 'end game' and 'waiting for Go(dot)', a position which was repeatedly interpreted as a self-blockade of an unfinished process of modernization, a path of development has (since the last decade of the twentieth century) been propagated which one could call a radicalization of modernity.

If it is true, that we have never really been modern, as was argued by Latour (1993), let's start it again. Modernity is no longer distinguished - as it was originally - as the 'new' in contrast to the 'old' (antiqui et moderni). Instead, innovation as such has been declared its essential characteristic. This is suggested in the self-descriptions of modern societies as 'knowledge societies' based on innovation and information. The contradiction of creative destruction (Schumpeter, 1942/1975) is per definitionem implied as movens: the foundation upon which one builds must be cleared away continuously, and the acceleration of renewal processes receive a value in and of themselves.

If it is true, that these supposed changes in the evolution of societies can be grasped in the changing concepts of time, then let's start there. The following different concepts and analytical aspects of time are referred to in this approach, presented in this volume: the tempo of social processes, the time horizon of expectations/orientations and the difference of simultaneity and non-simultaneity. ${ }^{1}$ Starting with two observations, these three aspects can be linked together in the following way:

The first observation is about the acceleration of 'just about everything' (Gleick, 2000), the speeding up of social processes, e.g. the spread of time saving techniques in every day life, shorter life-cycle of products, an ever higher pace of innovation, rapid prototyping, first-to-market strategies etc. However, the acceleration of social processes induces more and more perverse 
effects (e.g. traffic jam, jet lags). The limits of speeding up innovation by rapid prototyping have become visible, when the economy-size Benz (baby-Benz) couldn't stand the 'elk-test'. A counterculture of slow motion, slow food etc. emerges.

The second observation concerns the limitation of structures in time and the erosion of long term commitments, e. g. the politics of deregulation and flexibilization at the macro-level, project-organization and fixed-term employment contracts at the meso-level. These tendencies may be induced by a growing sensitivity for path dependencies and irreversible, time binding effects of decisions, in the ecological as well as in the economic system (Brose, 2000). Comparable evolutions can be found at the levels of private households and families, in lifestyles and value orientations of individual actors.

But the pitfalls of short term orientation of economic organizations and collective actors in the political system become more and more apparent, e.g. in the problems of the social security system or ecology. A politics in the shadow of future generations, of sustainability, has, many years since become an issue for social movements. Thus we witness contradictions of speeding up and slowing down processes of social change, of different time horizons of collective actors in different social sub-systems.

The first attempt to overcome these seemingly contradictory observations or trends, is to go beyond these alternatives of speeding up or slowing down social change, beyond the alternative of short-term or long range orientations, to search for empirical examples, where these alternative patterns of orientation co-exist and produce synergies (see Baeriswil, 2000 and Brose, 2001). The second attempt to go beyond the above mentioned alternatives is a more analytical one.

Speeding up processes and the shortening (or variation) of time scopes are as evident the causes as the outcome of an increasing simultaneity of events in the 'world at reach'. More and more rapidly varying events seem to appear on our different screens, overlapping and blurring the rhythms of our everyday life (e.g. work and leisure) and life-courses, breaking the gendered coupling of work and education. As the functioning of the ordering principles (first things first) and synchronizing mechanisms (calendars and clocks) cannot be taken for granted any more, are we deemed - like with television - to zap around? According to some critics, this kind of simultaneity functions as a black hole, absorbing all temporal differentiation, creating a 'timeless time' (Castells, 1996: 462). Though very suggestive, this metaphor seems to be misleading. Time matters (Abbott, 2001), perhaps more than ever in the last decades: It is the uncoupled, not synchronized diversity of different times, that challenges our society.

We therefore want to examine a bit more closely, how these different times and the diversities of time are conflicting, interacting or are 'living together side by side ${ }^{2}$ - probably not in harmony - but possibly in synergy. 
TIME \& SOCIETY $13(1)$

\section{Acceleration and Deceleration}

That the different tempos and especially the speed and acceleration of social processes become an issue in social life and discourse, is not new at all. In his essay on the 'Flaneur', Walter Benjamin (1973) notes that around 1840 it became fashionable to walk turtles on the streets of Paris. An early protest against the pace of modernity. Examples of the fearful perception of the 'acceleration of history' in the seventeenth century are reported by Kosellek (2000). In certain periods, social processes may appear as being too slow or too fast, a phenomenon which can be classified as 'cultural lag' (Ogburn, 1964). C. W. Mills (1959/1967) hints at the underlying interests of social actors: 'The notion of "cultural lag" . . suggests the need to change something in order to "bring it into line" with the state of progressive technology. Whatever is thought to be "lagging" exists in the present, but its reasons-for-being are held to lie in the past' (p. 88). Cultural struggles arise about the right speed and the need for acceleration (Glotz, 1999).

We may leave open, whether the perception of acceleration in our contemporaneous society is only a recurrent issue, raised preferably at the turn of centuries (as is sometimes argued) or whether acceleration has become an independent dimension of social evolution, as argued by Rosa (2003).

For our purpose, the semantics of speed, acceleration and deceleration hint at and partially mask two more important phenomena: 1 . The (mal-functioning of) synchronization resp. the simultaneity or non-simultaneity of processes and events (see section 5); and 2. The combination of acceleration and variation or innovation. The acceleration of processes such as transport, the search for information etc. often repeats 'the same as before' but faster. This may have 'only' time-saving and cost effects. This is nothing new for capitalist rationalization. It is more interesting if the time 'saved' by acceleration might be used for other activities or as an open space for alternative options (Brose, 2000). Then acceleration is possibly producing variation. Still more important is the acceleration of $R \& D$ processes, aiming at new inventions and its rapid implementation: innovation. The same holds for variations in time-scopes, e.g. by fixing (short) terms for socially expected durations, for example in fixed-term employment contracts or the organization of work processes in projects (Boutinet, 1996), limiting the time binding commitments. After the end of the project, a different one can be started. Let's therefore have a closer look at the problems of the variation of time-scopes/horizons. 


\section{Short-termism and/or Sustainability}

\subsection{The culture of short-termism}

In his book The Corrosion of Character, Richard Sennett (1998) describes the 'culture of new capitalism' as one of short-termism. He claims that the operational changes in economic organizations, which orient themselves toward short-term profits, have eaten away at the cultural foundations of capitalism. According to Sennett, the ascetic lifestyle oriented towards the ideal of restless but permanent professional work has lost its persuasive and legitimating power in the era of Casino capitalism and shareholder value orientation. The old work ethic, based on the ideal of deferred gratification patterns, self-discipline and long-term and constant effort, had contributed to social integration. However, those employed in the new 'disorganized capitalism' (Lash and Urry, 1987) are changing from people with job identities to participants in a game in which effort doesn't count anymore, only success. This promotes the opportunistic pursuit of interests and destroys trust-based coordination mechanisms and social relationships - also beyond work. Thus, also the foundations of social cohesion in ethnic and cultural communities are destroyed. In addition, the new forms of cooperation, such as teams, mask the true structures of responsibility and power, thereby disguising the structural context and making it unreadable. Sennett therefore intimates a connection between developments of time and the organizational structure of work with the apparently resulting signs of the disintegration of a social character, which according to Max Weber (1905/2001) had once contributed to the development of Western Rationalism. And Sennet points to the risks of a 'corrosion of character' in an era of short-termism, when longterm obligations and commitments seem to become dysfunctional and are thus avoided by organizations and individual actors.

One can ask the question whether or not Sennett's culturally critical diagnosis fits, and especially if it could persuasively describe the situation in European countries or in the United States. Doubt would be appropriate in this case. Let's assume first that the developmental tendencies described by Sennett could at least apply at the structural level. One could refer to the fact that the tendency toward long-term membership in organizations is decreasing, that employment relationships are characterized by discontinuities, that cooperative relationships are increasingly fleeting and unstable, and that the 'rules of the game' promoting clear responsibility and trusting relationships are losing their relevance. These aspects of the current development of work structures have become part of the German and international discourses, e.g. with the concepts of the boundary-less organization, decentralization and flexibilization.

Before trying to empirically evaluate the assumed tendency towards a culture of short-termism, to look for evidences and counterevidence, it is helpful, to 
TIME \& SOCIETY $13(1)$

have at look at the typical different time-scopes in the economic as well as the cultural system.

\subsection{Time-scopes in different subsystems: economy and the cultural system}

The functional short-termism of economic systems

Let's assume, as Luhmann (1988) does, that the function of the economic system is to secure scarce goods for a fundamentally unknown future and that this works based on the regeneration of the economic system's actors' ability to fulfill payment. If this is true, then we may deduce that this orientation on an uncertain future requires decisions in the present which are made under conditions of uncertainty. According to the prevailing view in economic science, this leads to the devaluation of the future and to a temporal preference or orientation towards short-termism. The actors in the economic system thereby operate with different scopes of time. While actors in the stock exchange deal with a shortterm view of time, banks transform short-term and long-term payment processes and operate with a mid-term view of time regarding their payment guarantees (Baecker, 1991). In contrast the time scope in a corporation is seen as comparatively long-term. The model of the short-termness of share holder value-oriented capitalism claims, however, that companies are increasingly shortening their operational scopes of time.

The function of culture: anchoring and latent pattern maintenance

Culture has traditionally been associated with the functions of preserving and binding. This applies not only to 'high' culture, from which artifacts are archived, becoming an essential part of the memory of society. It also applies to everyday culture, corporate culture, etc. Concepts developed by 'avant-garde' or 'pop-culture' reproduce this binding function, either in opposition to the idea of high culture or in its impulses for its renewal. The anchoring of socioeconomic evolution in traditions, with their long-term effects, and the 'nesting' (Polanyi, 1944/1995) of traditions in value commitments increases the adaptability and variability of those socially functional systems which specialize in this. Accordingly, cultural change takes place relatively slowly in comparison to technical and economic change.

If we simplify our perspective on economic and cultural systems, we can say that economic systems functionally follow a more short-term modus, and that cultural systems functionally tend to 'complement' or balance out the prevailing time scope through slowness and recourse to the past. This could be considered a common reference point among otherwise different definitions of 'culture' and may be seen as the handed-down inventory of deeply anchored, normative and symbolic orientations, or it may even be the 'memory' of societal systems which serves the function of latent pattern maintenance. Of course, this applies 
particularly for action systems such as education and socialization which are especially relevant in the cultural system as carriers of basic cultural techniques and orientations. And it seems apparent in this context, that socio-cultural development is also showing signs of shortening its time scope. A development trend toward short-termism, acceleration and transience in the cultural system would therefore be a confusing and embarrassing finding.

\section{Beyond the Alternatives: Acceleration vs Deceleration, Short vs Long-term Orientation}

As a matter of fact, one can observe different perspectives which have developed as evolutionary variants opposing the trends toward transience and acceleration. Examples include the normatively motivated attempts or reactive developments which try to work against the contemporary 'needs to clear out', for instance through new institution building, museization (Musealisierung) and renaissances of slowness (Reheis, 1998; Brand, 2000). And - still more interestingly - there are remarkable examples of sociocultural evolution which tie together the adaptability of dispositions toward transience with the tradition generating (tradierbare) long-termness and connectivity of cultural goods. A good example is the modern technology of publishing books on demand. This combines the short-termness of capital-investment (due to zero stocks) and the quick production of books with the long-termness of making available a cultural good (that otherwise would have been 'out of print') and the preservation of a specific kind of writing and reading culture. In the following paragraphs, we will look at some of these examples which go beyond the alternatives of acceleration or deceleration, of short-term or long-term-orientation

\subsection{Discontinuity management in the economic/employment system}

Even in light of the conditions of the contemporary shortening of time scopes, there appear to be moments of development which not only set limits on and work against the culture of short-termism, but also seem to transform this transience into new forms to connect short and long-termness. Examples from the field of regulation of employment relation and of social welfare make this clear. Thus with the so called employee deployment law (Arbeitnehmerüberlassungsgesetz) Germany has institutionalized a new employment form: Temporary work. Employees with relatively long job tenure in a temporary employment agency are sent for short-term deployment in various companies. ${ }^{3}$ Through the transformation of employment time spans the discontinuity of each deployment can be converted to a longer-term employment relation. Also in welfare-politics, the principle of 'transforming' (un-)employment spells is 
effective in those cases where for instance family related interruptions of access to insurance are brought into an overarching continuity due to socio-political structuring recognizing the validity of these periods of absence.

Current analyses of the dynamics of operations in economic organizations often emphasize their acceleration and short-term orientation, if compared with era of fordist mass-production. The shortening of product life-cycles and increasingly short time-spans for employment relations and organizational structures (projects) are seen as empirical evidence for this claim. The cause for this 'speed' and discontinuity management is seen, e.g. in the turbulence of organizational environments, for which the finance market gives an especially spectacular example. The strongly expressed uncertainties of future developments compel companies to take short-term strategies of profit-realization and dramatically increase the need for decision-making.

Although this diagnosis reflects important characteristics of current developments, it doesn't go far enough empirically and analytically. It is not only the case that strategies of short-termness appear to be reaching their limits in some economic fields, for instance in the fashion and software industry. Who buys the very newest version of a word processing program, when the one after that has already been advertised? And also in the field of product development the perverse effects of further acceleration can be seen, e.g. in the 'spectacular' experiences with the rapid-prototyping of the A-Class Mercedes (the baby Benz). The tendency toward accelerating research and development and shortening time binding effects is possibly not only reaching its limits. It is accompanied by complementing strategies which make possible new forms of longer-termism. For example, the market and customer orientation that is being propagated everywhere is not only an attempt to observe the volatility of the market in order to react in a timely manner. It is also part of the attempt to secure customer commitment by proactively influencing the future developments in demand through innovation, thus getting a the pioneer-bonus. The contingency and discontinuity of future developments can be limited and bridged in this way. Special forms of marketing, brand-sales strategies or service offers and the implementation of call centers should contribute to managing and binding the wooed customers.

The short-termness of market developments is thus implemented but also reflexively broken: The acceleration of processes and the limiting of commitments is accompanied by the utilization of the gained manoeuvring space to increase expectation certainty and integration in the environment. From this temporal perspective we can also win a deeper understanding of the discussion on making structures flexible and on network corporate organization. An informative example in this context is that especially the organization of innovation, which is supposed to bring about discontinuity, is often implemented in the form of network cooperation, which to a degree functions as an assurance game in light of the risks of innovation (Rammert, 1997). 
Linking economy and everyday culture (auto-)mobility

Alternative mobility concepts are also interesting in this context. The concept of the micro-compact car Smart marks the most significant break with the idea of the car as a 'sport-travel-limousine' (Canzler and Knie, 1994). On the one hand it is an example of the most advanced implementation of 'just-in-time' production, thus coming closer to the ideal of 'production on demand' (Bienzeisler and Brose, 2000) where parts of the final assembly take place at distribution centres. In this way the customer can also make last-minute choices concerning details of the design (e.g. color). Ordering and delivery both take place in a very closely timeframe. Short production and delivery times and a flexible final design according to the wishes of the customers make the Smart an example for shorttermness and speed in reacting to demand swings. The limitation of the use function (two-seater car) and the scope (local traffic) make the car relatively inadequate for long drives. At the same time the buyer of the Smart receives a free membership in a supra-regional network of car-sharing companies and discounts for car-transport when using the German rail system. The limitations to the local area and the short-termness of use is meant to connect it to supraregional and varying transportation forms. And the inexpensive and short-term variability of design make the Smart a partially 'recyclable' product. This should indicate that these forms of discontinuity management could definitely be seen in the context of ecological concepts of sustainable use, an idea which cannot be further expounded upon in this context (see also Bittlingmayer, 2000).

\subsection{Culture and short-termness: evidence and counterevidence}

There are the 'visible' aspects of change in the accelerated tempo in our lives and in the 'accelerated obsolescence' of the knowledge inventory in a society that focuses completely on innovation. But also at the structural level, in the educational system and in the field of primary socialization, the expressions of transience cannot be overlooked. If one just concentrates on the duration and disintegration of first marriages, one sees that the stability of families and household constellations has declined significantly. Also the type and course of gaining knowledge in educational institutions can no longer be understood as an unquestioned stage of preparation for the later application of such gained knowledge. The current discussion in German universities reflects this and even in the stronghold of certainty and long-lastingness, the legal system, laws are being prepared to ensure an acceleration in administration (see Cwerner, this issue). Not to mention the transience of political decision scopes. Of course, especially in the legal field it has become clear that attempts to make short-term changes in energy politics fails due to the long-term binding effects of concluded contracts. But it is not difficult to see the signs indicating that (also) in 
the cultural system short-term thinking has gained in significance. Nevertheless, there is not only still a (relatively) long-term time horizon in the cultural and institutional field; there are not only massive and widespread efforts to counter the increasing tendencies toward acceleration and shortening time scopes by 'anchoring' the present socio-cultural development in the different expressive forms of cultural heritage and its diffusion. Examples include the contemporary importance of making the present into a museum object (the museization of contemporary society) as well as the general tremendous increase in the number of museums, which make clear this need for 'anchoring' in the cultural field. The debate surrounding the reconstruction of the Berlin City Palace is one informative example. Before turning to the specific sphere of culture, monuments and museums, it is worth having a look at the changes in our meaningful organization of time through the semantics of time.

\section{Changes in the Social Awareness of Time}

The social awareness of time can be understood as a perspective on or observation of states and changes in society. In the analysis of time awareness, one tries to reconstruct the categories and differentiations operating in this perspective. Some examples are the categories 'Movement', 'Event', 'Change' or 'Longterm', or the differentiation between 'time vs eternity', 'old vs new' or 'before vs after'. According to the socio-historically varying differentiations / observations, experiences are ordered and sorted, expectations are structured, actions are planned and especially causalities are constructed.

'Pre-modern', so-called cyclical, time awareness repeatedly returns back to what it was before and preserves its time perception of 'sameness'. In contrast the modern time perception emphasizes the phenomena of non-simultaneity, of discontinuity and - above all - the difference between before and after, past and present. Depending on one's perspective, this differentiation, as the experience of newness or innovation, is either praised or criticized and can lead to either pessimistic or optimistic expectations and interpretations. With this emphasis on ruptures in modernity, a linear time awareness acquires the function of bridging the ruptures in order to construct a continuity. This continuity makes possible the connecting of 'before' and 'after', expectations and actions, but especially the reconstruction of causalities. With the secular adjustment of time awareness to this kind of observation, the present lost its own' orientation value, its meaning. It shrank to a knife-edge present (Mead, 1932/1980) a switching point between the future and the past and placed actors under increasing time pressure. This was not a problem as long as the future could still be seen as 'open', a place wherein the developing newness could be projected and positioned. To the extent that the (unintentional) consequences of modernization 
processes have become increasingly apparent - e.g. in the field of ecology - this form of 'defuturizing' (Luhmann, 1976) doesn't function unquestioned anymore. Instead, there is significant pressure to justify such thinking. In this way, the present has gained strength within the horizon of time awareness as we can observe it. It can no longer only be a switching point, in which the future is constantly transferred into the past. It must rather become a manoeuvering space for future possibilities and thus for decisions. It potentially becomes an 'extended present' (Nowotny, 1988) in a quasi-simultaneity.

\subsection{Simultaneity and the awareness of the present}

Simultaneity and non-simultaneity are basic features of the social constitution. According to Mead (1932/1980) sociality is 'the capacity of being several things at once' (p. 47), e.g. the ability of an actor to be simultaneously himself and an other person and thus - by anticipatory reactions - coping with the problem of double contingency. Luhmann (1990) - in conformity with phenomenological philosophy - makes the assumption, that everything that happens, happens simultaneously (see also Nassehi, 1993). This holds true, relative to an observer who starts with the distinction: Now/not now and in the next step can use the distinction: Before/after with reference to events that have happened (in the past) or will possibly happen (in the future). Thus non-simultaneities and simultaneity are intrinsically linked. The handling and observation of their difference becomes part of the temporalization of complexity (Luhmann, 1987). Synchronization works with these basic features through temporal ordering, using calendars and clocks to arrange, for example the temporal simultaneity of acts and events, where different people are doing different things, e.g. in the division of labour and services in work-organizations, or in the multi-tasking work profiles of professionals, where the same person is doing different things simultaneously.

In actions and experiences which take place simultaneously, causalities cannot be 'built-in' any more: There is no before and after, they are not subject to influence. The acceleration of such actions/events, processes increases their inaccessibility. In our globalized societies with their virtual omni- and everpresent through television and telecommunication, a consciousness is growing with respect to simultaneity - and thus the in-accessibility - of experiences and processes in an increasingly complex world society. It is not only the tempo of processes that is speeding up; not only the limitation of time horizons and the shortening of 'socially expected durations' (Merton, 1986) that challenges our temporal organization. Speed and acceleration and the shortening of timescopes are the causes and effects of change in our forms of temporal differentiation. Such differentiation may be of greater importance. The differentiation of time into the before/after relation, the temporal ordering by sequencing (and 
hence queuing and waiting) is complemented by a temporal differentiation in co-existence, by the intersection of time and space (Bergson 1889/1910) and hence simultaneity. When the (virtual) spaces are changing, as a consequence of migration and globalization, the space-time intersections, i.e. the simultaneities, do so too.

Yet though the exigencies and abilities of dealing with simultaneity increase, the possibilities of simultaneous processing are limited or turn out to become chaotic. Coping with (more) simultaneity uno actu produces a (growing) realm of non-simultaneities. That is - seen from a functionalist perspective - the problem to be solved.

\section{Living with Different Times or Living in Different Times?}

Different time horizons and different rhythms or tempos have always existed in society, particularly in modern societies. These are differentiated into functional sub-systems whose boundaries allow for the development of different temporalities and tempos in their respective systems (and their organizations). They are synchronized and integrated by institutional arrangements and - in the Parsonian version of systems theory - by the cultural system, that serves the function of latent pattern maintenance (Parsons, 1965). The (different) speed(s) in the different systems thus could be controlled by the 'land factor' of culture. In the diachronic dimension, the different times can be turned into the continuity of tradition, and in the synchronic dimension the normative structure is ordering the co-existence and succession of commitments and events. Thus, in a given society, at the same time, different temporalities coexist. At the individual level, we could say that at the same time there are people living together, but in different temporalities of different roles. Thus, the co-existence of different tempos and temporal horizons would be nothing but the very proof of the functional differentiation of society. But in our contemporary society, something seems to be different.

The synchronization of the very different tempos and temporal horizons seems to function well, if they are existing apart together, within the boundaries of their respective subsystems and organizations, but integrated by an institutional regime and a temporal ordering of events. This ordering, like the institutionalized life-course or the fordist accumulation (and gender-) regime, separating leisure time and working time, is based on differentiation and sequential ordering. Here we could speak of the non-simultaneity of the simultaneous. Today, one can argue, we have to cope with the problem of the simultaneity of the non-simultaneous.

The concept of non simultaneity was (not first, but most prominently) used by Ernst Bloch (1935/1991), a German philosopher, in his 'Erbschaft dieser Zeit' 
(Heritage of Our Time). For him this concept refers to the fact that people are living together at the same time, but not in the same time. Therefore I would translate Bloch's concept as the 'non- contemporaneity' of the contemporaneous. ${ }^{4}$ It refers particularly to different mentalities and time horizons of social classes, that may either stick to their traditions or are striving for an utopian idea (see also Giesen, this issue).

In our contemporary society we witness some relevant tendencies, that transform the differentiation in succession into a differentiation in co-existence, to use the (translated) terms of Georg Simmel (1890: 144). ${ }^{5}$ I would speak of a differentiation within simultaneity: Keywords would be: Multitasking, Flexibility, Simultaneous Engineering etc. And last not least, a prime example is the multi-culturality within the context of European Unification and transnational, post-colonial migration.

By social, economic and technological developments (telecommunication, television, globalization, [virtual] mobility (Zoche, Kimpeler and Joepgen, 2002)) the uncoupled co-existence of events and cultures - beyond the 'world at reach' - is brought into a new simultaneity. ${ }^{6}$

As a consequence, the synchronization of different temporalities becomes a problem again. Mobility, migration and the acceleration of technological change make this kind of simultaneity of non-simultaneous events, artefacts and actions still more sensible. The cultural struggle for speeding up or slowing down social and cultural change, thus can be understood as an attempt to synchronize the non-simultaneous trends, interests and orientations. The same holds for the 'cultural struggle' between those arguing for sustainable development and those manoeuvring in an extended present. But beyond these claims, we may witness the emergence of new practices and structures, how to live and work with different temporalities, without bringing them necessarily into a hierarchical linear or sequential ordering. That is, what I call the culture of non-simultaneity. This assumption has to be analyzed at different levels of social constitution: Interactions, organizations and societies resp. their functional systems.

Here the assumption is made, that if there are empirical indicators for a change in temporal differentiation, emphasizing the co-existence of different temporalities, they should also be found in the cultural system.

\section{Cultures of Non-simultaneity}

\subsection{Museum architecture}

Museums are an important part of our cultural system. They collect and conserve artefacts and create classifications and evaluations by decisions about collecting/buying and expositions. They organize parts of the collective 
memory by representing and re-constructing the past, by periodization and by the historization of the present. They also produce transhistorical 'simultaneities', by qualifying artefacts as 'classical' and time-resisting, as having a transhistorical aesthetic value (Assmann, 1999). It therefore makes sense to use the metaphor of a 'time machine' (Lumley, 1988) with respect to museums. And different museums operate with different time-machines resp. models of time. With respect to the British Museums in the late nineteenth century, Lumley (1988) makes the following assessment: 'In fact, a model of time as "progress" or evolution, moving from lower to higher forms, underpins the philosophy of the late Victorian museum and its spatial organization' (p. 6).

When looking at contemporaneous Museums, what models of time do we find in use? The extension of the Victoria and Albert Museum, planned by Daniel Libeskind, might be a good example to start with.

Time and space - architecture and temporal structure: spirals - between the lines - voids

The project for the extension of the V\&A Museum called 'The Spiral' by Libeskind (2001)(see Figure 1) is planned to link different ailes of the existing building by a "continuous wall, whose extent mirrors that of the perimeter walls of the entire V\&A block, spiraling around a virtual and ever shifting vertical axis' (p. 156).

'The Spiral is a unique structure. It is not a traditional spiral with a single centre and axis, but a contemporary spiral which opens a plurality of directions along many different trajectories, providing multiple routes, spaces and ambiance for the visitors. The building utilises a simple, continuous, interlocking wall system to create and articulate functions, while offering an efficient and flexible structure requiring no supporting elements. (p. 157)

... The winding and unwinding of the spiral creates an interlocking of the inside and the outside of the new building, bringing the visitors into close relation with history and the present, the city and the museum, through a direct experience of interpenetrating views of the existing facades and the skyline of London, while from the old museum block one is reoriented by the shifting movements of the new building'. (p.156)

It seems, that the form of a spiral is particularly suitable for built spatial articulations of different historical perspectives. The recently opened extension of the German Historical Museum in Berlin, planned by I. M. Pei, also uses a spiral staircase, to link the different floors of the museum. This spiral staircase, surrounded by walls of glass, climbs up the building in the outer side, thus opening up views of the different levels of the new and old building, the baroque Zeughaus, all at once.

Another striking example of architecture, that transforms the simultaneity of non-simultaneous histories into a spatial and bodily experience is the Jewish 

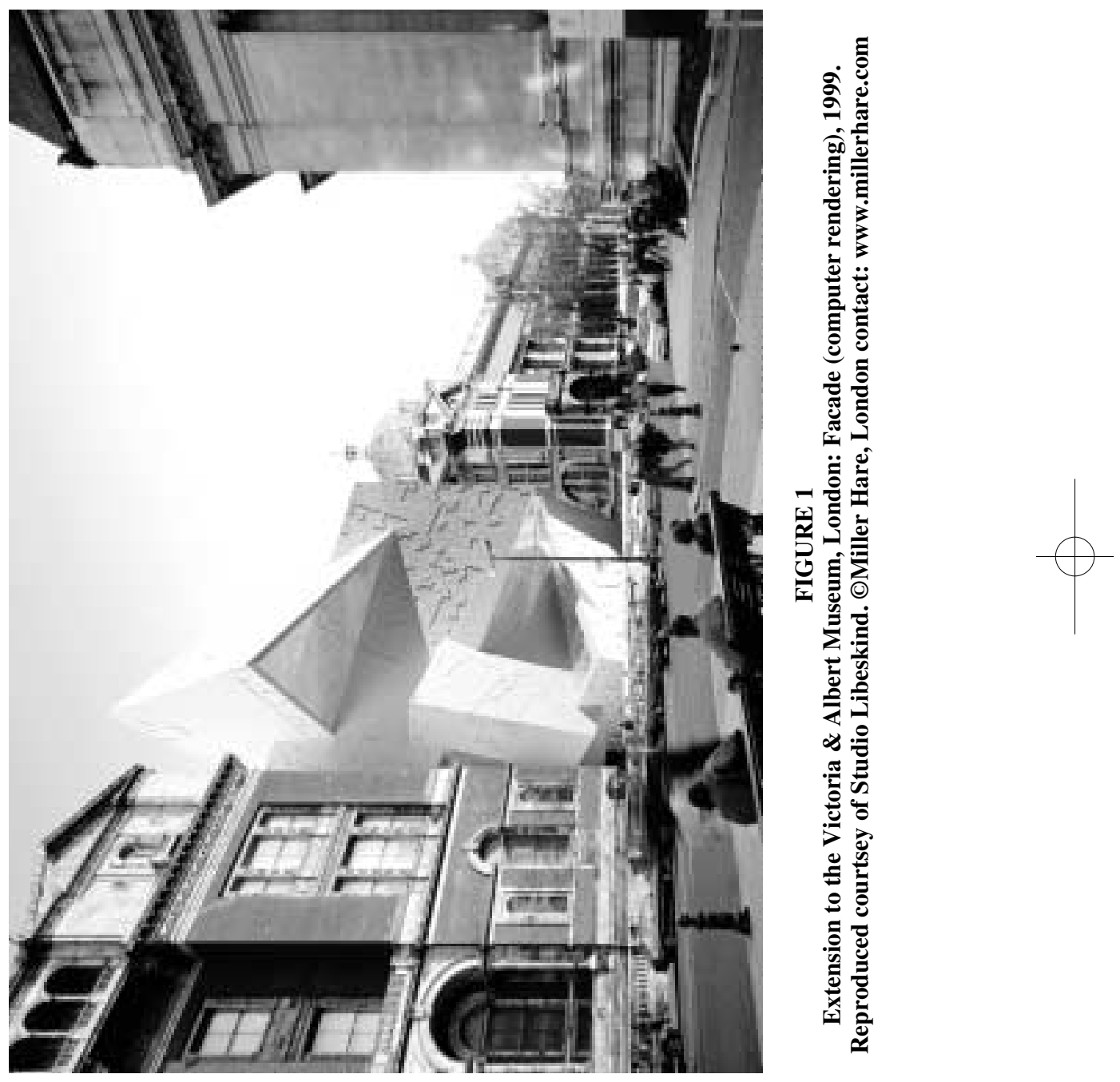
Museum in Berlin, also planned and built by Daniel Libeskind (see Figure 2). The name of this project was 'Between the lines'. Libeskind (2001) explains:

'I call it this, because it is a project about two lines of thinking, organization and relationship. One is a straight line, but broken into many fragments; the other is a tortuous line, but continuing indefinitely'. (p. 23)

and

'When this building seemed simply a theory, people described its foundation as a zigzag, or a blitz, surely an image only seen by an angel. Today, as you walk through the building, the walls, exhibition spaces, and the building's organization, generate an understanding of disrupted tradition - and the trace of the unborn. The main doorway to the museum is through the baroque Kollegienhaus, the former Prussian Courthouse ... Programmatically, it is important to enter that baroque Berlin with all its rich history and then to descend through the entrance void to the underground connections. These connections link the visitor with the new Jewish museum - an underground connection which asserts the profound foundation between the German and Jew. There are three streets, each having a singular destination: The Garden, The Holocaust Tower, and the Stair of Continuity. The Garden is upside down, containing forty-nine columns in a rigid grid and on a sloping surface. Forty-eight of these columns are filled with the earth of Berlin, signifying the birth of the state of Israel in 1948; one representing Berlin is filled with the earth of Jerusalem. The garden is upside-down because the vegetation grows across only at the very top and is completely hidden in the 7-meter high columns. Upside-down because there is a distinct disorientation produced by perfect right-angle geometry rooted in a sloped floor vis-a-vis the buildings surrounding it ... Another road ends with the Holocaust Void, an abrupt dead end. This 27-meter-high acutely angled space is built of raw concrete ... There is only a reflection-without-source of a narrow line of light, which ends high above. This chamber resonates with the hum of the city. The Holocaust Void is a place that has to be experienced as an end, which will forever remain a dead end. For they will not return. The third and longest road leads to the main stairway and to the continuation of the museum, giving access to the different exhibition floors. The central structure in the building is the void, a disconnected straight line, cutting through the building. This void - different acoustically, materially, architecturally from the white walls of the exhibition spaces and illuminated by skylights - refers to that which can never be exhibited in this museum, no matter how many objects are brought to it and stories told in it. The bridges provide the physical connection from one side of the museum galleries to the other'. (pp. 25-7)

The void doesn't give the impression of an 'abstract sign of negation' (pp. 25-7), but is rather 'built into' the architecture, where confusing lines actually do lead to overlaps and repeated meetings in historical rooms and times. This suggests a variant of dealing with historical time beyond chronology, linearity and sequences which is still capable of ordering continuities, catastrophes and discontinuities in historical and cultural development. 


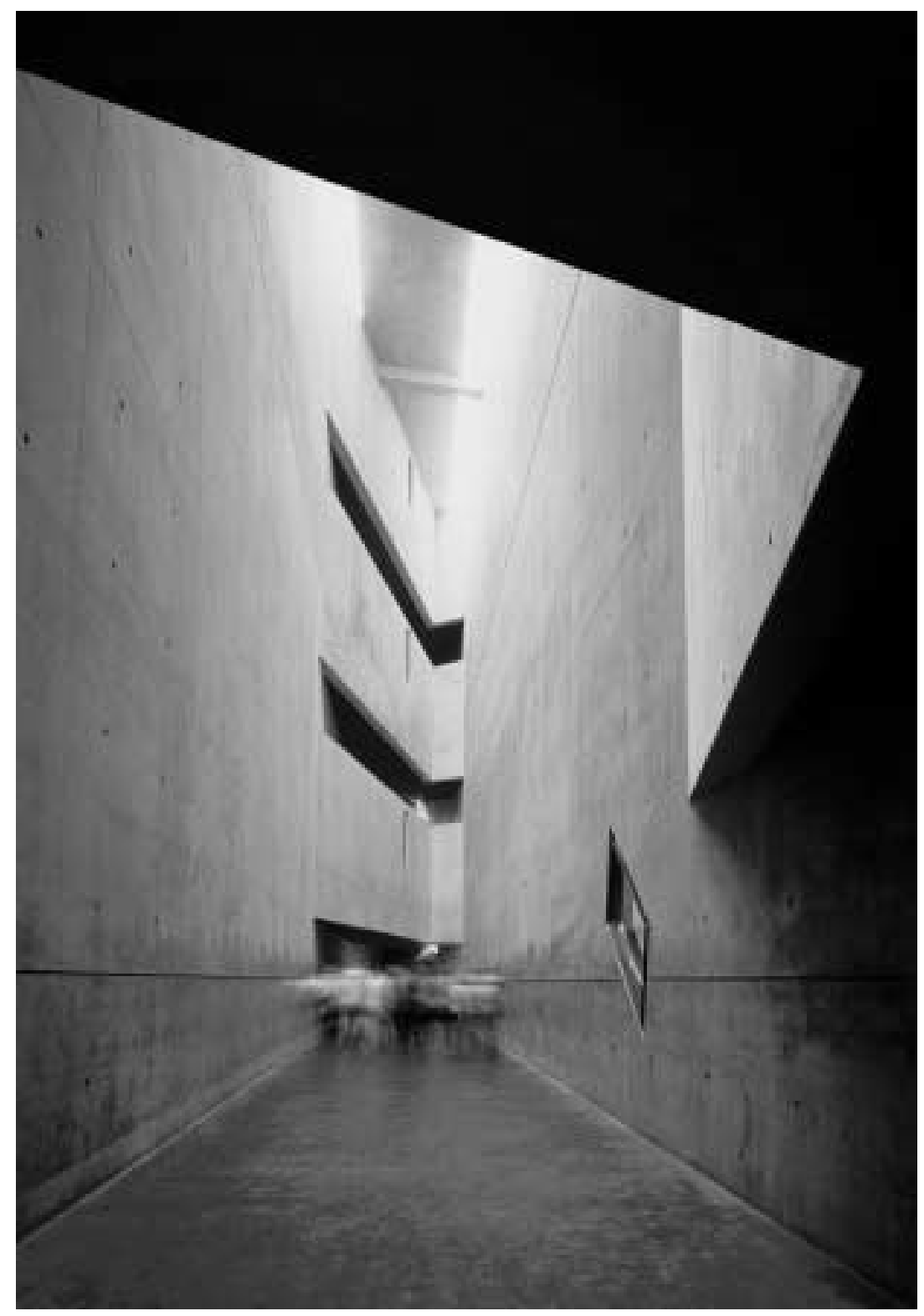

FIGURE 2

Jewish Museum Berlin: 6th Void, 1999. Reproduced courtesy of Bitter+Bredt. OBitter+Bredt, Berlin contact: www.bitterbredt.de 
TIME \& SOCIETY $13(1)$

\section{The Contributions of the Volume}

The empirical indicators for new ways of coping with different temporalities so far are what have been called a 'management of discontinuity' in the economic and the employment system and a culture of non-simultaneity, as in the cases presented earlier of historical museums. The contributions of this volume refer to other empirical settings: Multiculturality, Mobility, Media and Memory. One common point of reference of these might be the changes in spatial dimensions of the World-Society and the Life-World. Post-colonial migration, globalization, (virtual) mobility, European transformation and unification and, last not least, telecommunication and television. These changes in the spaces of our world at reach - including the world we can remember - are intrinsically linked with the temporal changes that are focused on in this volume.

The first two articles make clear and remind us, that different temporalities or 'temporal inconsistencies' (Giesen, this volume) are neither surprising nor avoidable phenomena in the constitution of society. They are, as Spurk argues, inherent to the human condition especially the historicity of human existence. By referring to Merleau-Ponty ('. . . our irreplaceable life, our wild freedom has already been foreshadowed, already been compromised, already been experienced in other freedoms of the past'), Spurk (this volume) makes clear that the social constitution is an ongoing dialectic of continuity, rupture and emergence, and concludes, that "although the "speeding up" process increasingly influences contemporary societies, society formation remains anchored to continuities, linking it to the past'. Giesen (this volume) insists on the normality of temporal hybridization and syncretism in real societies and distinguishes three different paradigms of temporal inconsistency: 'Noncontemporaneity', which refers to the coexistence of phenomena related to different historical periods; 'asynchronicity', that focuses on differences of pace and rhythms of different social systems and a third model which he calls 'divided memories' that differ with respect to their experiential especially generational background. But, as a matter of fact, these generational differences, (formerly) rooted in the collective experience of core events and helpful for the construction of collective identities, seem to be fading away, or blurring, as Giesen states. Might that be a kind of emerging generational contemporaneity or simultaneity? And couldn't the inflational construction of new generations in the public discourse, that Giesen observes as well, be explained by the need for non-simultaneities as points of reference in the meaningful organization of interests and identities of different age-cohorts? And the division of memories? Doesn't it exist any more, if generational differences are blurring? Or is our memory possibly collapsing, as a consequence of a 'view of the world as a perpetual and pervasive present through the real-time lens of television news', as Hoskins (this volume) argues in his contribution to this volume? Another answer would be that the memory 
and its differences apparently do not become irrelevant. But the sources of the memory divide may have shifted. They are stemming (now) from different (cultural) pasts, as in the case of the German unification, or in different religious commitments, as in the case of the conflicts about Islamic religious practices (see Wohlrab-Sahr, this volume) and their judicial solutions. By law, nation states try to synchronize the different temporalities, induced by 'a new phase of globalization of migration' (Cwerner, this volume), through a speeding up of the asylum process, as in the UK and other countries of the European Community. The attempts, to 'integrate the simultaneity of different pasts' (Wohlrab-Sahr, this volume) seem to be limited to such 'religious practices, that are not connected to future projects'.

Another way of dealing with a-synchronicity is the process of Europeanization, which Klaus Eder (this volume) treats in his contribution:

'It (the process of Europeanization) synchronizes by standardization and by the timing of standardization. Thus it creates a situation in which non-synchronicity is generated at increasing speed ... Thus the case of the New Europe is a particularly striking case of an emerging culture of the simultaneity of the construction of non-synchronicity and synchronicity.'

While most of the contributions mentioned so far argue at the macro level of institutions and traditions, the last two articles in this special volume are concerned with the interface of individual actors as users and consumers (and producer) of media: Televison and the Internet. Hoskins advocates that 'a shortening of temporal horizons, diminishing attention spans and a saturation of time and place' can be said to be 'the characteristics of our mediated age' and suggests that there has occurred a 'collapse of memory' with reference to newsreporting formats. Ursula Holtgrewe (this volume) undertakes another 'reading' of the medium Internet: 'The Internet is widely considered as a key factor of speeding up social and cultural change. It . . . enables flows of information and capital, and communication and co-operation regardless of space and possibly time'. This is in particular, what Castells refers to, when he is speaking of 'timeless time'. Holtgrewe's article 'explores the example of Open Source/Free Software' development, and shows, that in this case, there can be found an escape of the 'all-encompassing simultaneity' of the Internet, and that practices of 'non-simultaneous involvement' occur and allow for the development of a sustainable creativity.

In sum, the contributions of this volume provide evidence and counterevidence of what was proposed as a working hypothesis: The emergence of a culture of non-simultaneity. It's up to further scientific discussion to decide whether the assumption of a culture of non-simultaneity is one that may inspire to further empirical research. 


\section{Notes}

I am very much indebted to the Kultuturwissenschaftliches Institut (Essen, Germany) that gave me the possibilty of organizing an International Conference: 'Kulturen der Ungleichzeitigkeit - Au delà du court terme - Speeding up cultural change?' in June 2002 at the Katholische Akademie Wolfsburg (Mülhheim/Ruhr, Germany) and further by granting me a fellowship at the Institut for the academic year 2003/4. This Special Volume presents a selection of the papers presented at the above mentioned conference.

1. This latter (non-simultaneity) stands for the German concept of Ungleichzeitigkeit. There are at least three possible translations for Ungleichtzeitigkeit: 'Noncontemporaneity', 'a-synchronicity' (see Giesen, this volume) and 'non-simultaneity'. The latter seems to me more appropriate for the argumentation, developed in this introduction.

2. To play with the John Lennon song 'Ebony and Ivory'.

3. It is not allowed for German temporary work agencies (TWA) to hire people just for one deployment. This is called the 'interdiction of synchronization' (Synchronisationsverbot) of the employment relationship with the TWA on the one hand and the work-relationship in the companies where the temporary workers are doing their jobs, on the other. It results a triangle of relations between the worker, the TWA and the companies, the temps are assigned to (Brose, 1989).

4. It also refers to Marx's concept of a tension or clash between 'basis and the superstructure', an early - and more complex - conception of what Ogburn later had called the cultural lag.

5. For Simmel (1890), the paradigmatic example for a differentiation in co-existence or 'simultaneity' is money (p. 145).

6. Meanwhile including parts of the 'World-Society', that were - behind walls and iron curtains - out of reach.

\section{References}

Abbott, A. D. (2001) Time Matters: On Theory and Method. Chicago: University of Chicago Press.

Assmann, A. (1999) Zeit und Tradition. Köln: Böhlau.

Baecker, Dirk (1991) Womit handeln Banken? Eine Untersuchung zur Risikoverarbeitung in der Wirtschaft. Frankfurt am Main: Suhrkamp.

Baeriswyl, M. (2000) Chillout - Wege in eine neu Zeitkultur. Munich: DTV.

Beck, U. (1986/1992) Risk Society: Towards a New Modernity. London: Sage.

Bergson, H. (1889/1910) Time and Free Will. London: Allen \& Unwin.

Benjamin, W. (1973) 'The Paris of the Second Empire in Baudelaire', in W. Benjamin (ed.) Charles Baudelaire: A Lyric Poet in the Era of High Capitalism, pp. 9-106. London: New Left Books.

Bienzeisler, B. and Brose, H. G. (2000) 'Herstellung auf Bestellung - Zeitstrukturelle Implikationen eines produktionslogistischen Konzepts', in H. G. Brose (ed.) Die Reorganisation der Arbeitsgesellschaft, pp. 205-38. Frankfurt/New York: Campus.

Bittlingmayer, U. H. (2000) Askese in der Erlebnisgesellschaft? . Opladen: Westdeutscher Verlag. 
Bloch, E. (1935/1991) The Heritage of Our Time. Cambridge: Polity.

Boutinet, J. P. (1996) Psychologie des conduites à projet. Paris: PUF.

Brand, St. (2000) The Clock of the Long Now. London: Phoenix.

Brose, H. G. (1987) 'Des nouvelles Valeurs - Notes sur la Modernisation du Temps', Revue Européenne en Sciences Sociales 74: 91-105.

Brose, H. G. (1989) 'Coping with Instability - The Emergence of New Biographical Patterns', Life Stories (5) : 3-260.

Brose, H. G. (2000) 'Vitesse et irreversibilité: aspects d'une nouvelle schématisation du temps dans les organisations du système économique', Informations sur les Sciences Sociales 39(3): 421-38.

Brose, H. G. (2001) 'Zeitkulturen im Umbruch', in G. Altner et al. (eds) Jahrbuch für Ökologie 2002, pp. 123-36. Munich: C. H. Beck.

Canzler, W. and Knie, A. (1994) Das Ende des Automobils. Heidelberg: C. F. Müller.

Castells, M. (1996) The Rise of the Network Society. Cambridge, MA: Blackwell.

Gleick, J. (2000) Faster: The Acceleration of Just About Everything. Turlock, CA: Abacus.

Glotz, P. (1999) Die beschleunigte Gesellschaft. Kulturkämpfe im Digitalen Kapitalismus. Munich: Kindler.

Koselleck, R. (2000) Zeitschichten. Frankfurt am Main: Suhrkamp.

Lash, S. and Urry, J. (1987) The End of Organized Capitalism. Cambridge: Polity Press.

Latour, B. (1993) We Have Never Been Modern. New York: Harvester Wheatsheaf.

Libeskind, D. (2001) The Space of Encounter. London: Universe Publishing.

Luhmann, N. (1976) 'The Future Cannot Begin: Temporal Structures in Modern Society', Social Research 43:130-52.

Luhmann, N. (1987) 'The Temporalization of Complexity', in F. Geyer and J. van der Zouwen (eds) Sociocybernetics, pp. 95-111. Leiden: Nijhoff.

Luhmann, N. (1988) Die Wirtschaft der Gesellschaft als autopoietisches System, in N. Luhmann Die Wirtschaft der Gesellschaft, pp.13-42. Frankfurt am Main: Suhrkamp.

Luhmann, N. (1990) 'Gleichzeitigkeit und Synchronisation', in N. Luhmann Soziologische Aufklärung 5, pp. 95-130. Opladen: Westdeutscher Verlag.

Lumley, R. (1988) 'Introduction', in R. Lumley (ed.) The Museum Time Machine, pp. 1-24. London/New York: Routledge.

Lutz, B. (1984) Der kurze Traum immerwährender Prosperität. Frankfurt am Main: Campus.

Mannheim, K. (1936/1976) Ideology and Utopia. London: Routledge and Kegan Paul.

Mead, G. H. ( 1932/1980) The Philosophy of the Present. Chicago: The University of Chicago Press.

Merton, R. K. (1986) 'Social Expected Durations', in W. W. Powell and R. Robbins (eds) Conflict and Consensus. A Festschrift in Honor of Lewis A. Coser, pp. 262-83. New York: Free Press.

Mills, C. W. (1959/1967) The Sociological Imagination. Oxford: Oxford University Press.

Nassehi, A. (1993) Die Zeit der Gesellschaft. Opladen: Westdeutscher Verlag.

Nowotny, H. (1988) 'From the Future to Extended Present ', in G. Kirsch, P. Nijkamp and K. Zimmermann (eds) The Formulation of Time Preferences in a Multidisciplinary Perspective, pp. 17-31. Aldershot: Avebury.

Ogburn, W. F. (1964) On Culture and Social Change: Selected Papers. Chicago: University of Chicago Press. 
Parsons, T. (1965) 'Introduction: Culture and the Social System', in T. Parsons, E. Shils, K. D. Naegele and J. R. Pitts (eds) Theories of Society, pp. 963-93. New York: The Free Press.

Polanyi, K. (1944/1995) The Great Transformation. Frankfurt am Main: Suhrkamp.

Rammert, W. (1997) 'Innovation im Netz. Neue Zeiten für technische Innovationen: heterogen verteilt und interaktiv vernetzt', Soziale Welt: 397-416.

Reheis, F. (1998) Die Kreativität der Langsamkeit. Darmstadt: Wissenschaftliche Buchgesellschaft.

Rosa, H. (2003) 'Social Acceleration: Ethical and Political Consequences of a Desynchronized High-Speed Society', Constellations 10(1): 3-33.

Schumpeter, J. (1942/1975) Capitalism, Socialism and Democracy. New York: Harper \& Row.

Schutz, A. and Luckmann, T. (1983) The Structures of the Life-World. Evanston: Northestern University Press.

Sennett, R. (1998) The Corrosion of Character. New York/London: W. W. Norton.

Simmel, G. (1890) Über sociale Differenzierung. Leipzig: Duncker \& Humbolt.

Weber, M. (1905/2001) The Protestant Ethic and the Spirit of Capitalism. London: Routledge.

Zoche, P. Kimpeler, S. and Joepgen, M. (2002) Virtuelle Mobilität: Ein Phänomen mit physischern Konsequenzen. Berlin: Springer.

HANNS-GEORG BROSE is Professor of Sociology at the University Duisburg-Essen, Germany. During the academic year 2003-4 he will be Fellow at the Kulturwissenschaftliches Institut Essen (Science Center North-Rhine-Westfalia). His Research Interests are: Sociology of Work and Organizations; Life-Course Research; Sociology of Time. Recent publications include Die Reorganisation der Arbeitsgesellschaft (Campus, 2000), Telekom - Wie machen die das? (UVK, 2002, together with D. Blutner and U. Holtgrewe). ADDRESS: Universität Duisburg-Essen, Standort Duisburg, Fakultät 1- Soziologie, D-47048 Duisburg, Germany. [email: brose@uni-duisburg.de] 